\title{
Evaluation of Lactate in Differentiating Pyogenic and Non-Pyogenic Meningitis
}

\author{
Mehul K. Patel ${ }^{\circledR 1}$, Hitesh J. Patel ${ }^{\circledR 2}$ \\ ${ }^{1}$ Assistant Professor, Department of Medicine, Gujarat Medical Education \& Research Society Medical College, Dharpur Patan, Gujarat, India, ${ }^{2}$ Senior Resident, \\ Department of Medicine, Gujarat Medical Education \& Research Society Medical College, Dharpur Patan, Gujarat, India.
}

\section{Abstract}

Background : Meningitis is serious and a life-threatening condition among any age group associated with serious mortality and morbidity. The objective of the present research was to assess the efficiency of CSF lactate in differentiating bacterial/ pyogenic from non-pyogenic meningitis. Subjects and Methods: A hospital-based one-year prospective study was conducted at a tertiary care hospital in Gujarat. The study was performed at the department of General medicine for a period of one year. All the cases suspected of meningitis above 18 years of age irrespective of sex were admitted and clinically evaluated. The Diagnosis of meningitis was made on account of various clinical symptoms and signs. Like headache, nausea, presence of kernig's sign, altered sensorium, cranial nerves palsies, hemiparesis, seizures, etc, Results: The mean total cell count was highest in cases of pyogenic meningitis with a mean of 840.50 and SD of 112.30 than viral and tubercular meningitis. However, no statistical significance was associated with total count and types of meningitis. $(\mathrm{P}>0.05)$ Lactate levels of the CSF were elevated than normal in both pyogenic and tubercular than viral, however, the mean CSF lactate was higher in pyogenic than tubercular. A clear statistical significance was observed in CSF sugar/blood glucose ratio and CSF lactate levels in this study ( $\mathrm{p} \leq 0.05)$. Conclusion: CSF lactate level is a rapid, quite inexpensive and unpretentious process, important diagnostic indicator in the premature demarcation of pyogenic meningitis and tubercular meningitis from viral meningitis, serving in the premature organization of proper action and diminishing transience and impediments. Early detection may help in early decision on the type and institution of appropriate management could reduce the mortality and morbidity of meningitis.

Keywords: CSF lactate, Kernig's sign, Meningitis, Seizures

Corresponding Author: Hitesh J. Patel, Senior Resident, Department of Medicine, Gujarat Medical Education \& Research Society Medical College, Dharpur Patan, Gujarat, India.

E-mail: hjpatelpatan@gmail.com

Received: 20 May 2020

Revised: 06 July 2020

Accepted: 17 July 2020

Published: 30 December 2020

\section{Introduction}

Inflammation of the membranes of meninges characterizes Meningitis - clinical syndrome that encloses the brain and spinal cord. Meninges's layer consists of the following: ${ }^{\text {[1] }}$ Dura mater - A hard and outermost membrane. ${ }^{[2]}$ Arachnoid mater: A web-like center membrane. ${ }^{[3]}$ Pia mater: the deepest layer which holds close to the brain. Subarachnoid space lies among arachnoid and pia mater and has many of the blood vessels that feed the brain and spinal cord. Meningitis can be grounded by various etiologies like tubercular, pyogenic and aseptic/viral. Meningitis is serious and a life-threatening condition among any age group associated with serious mortality and morbidity. The cause may be bacterial, viral and also fungal with a different set of morbidity and severity. Differentiating bacterial from viral by clinical signs and symptoms is relatively challenging to the clinicians. Bacterial meningitis is associated with severe mortality and post sequelae than viral and fungal meningitis. Prompt diagnosis and appropriate antibiotic therapy are required to reduce mortality and morbidity. Any delay in diagnosis and appropriate therapy will worsen the prognosis. Hence early and rapid separation amid bacterial and viral meningitis is essential in the premature beginning of treatment. ${ }^{[4]}$ Meningitis can be caused by various etiologies like tubercular, pyogenic and aseptic/viral. Meningitis is a major universal health subject, mainly in developed countries. Among various types of meningitis, pyogenic meningitis is a frequent communicable disease of the CNS in India. Meningitis a critical disease connected with notable morbidity and mortality. ${ }^{[2]}$ Moreover, long-standing development such as palsies, hearing loss and personality modify influence about $40 \%$ of survivors. ${ }^{[3]}$ The worldwide dis- 
tribution of Pneumococcal, Haemophilus, and meningococcal meningitis has been observed and mainly in young age groups. frequency of meningitis has substantially condensed in developed countries after the introduction of vaccines against these agents. For identifying the cause of meningitis, clinical features, routine CSF parameters, and radiological findings are often inadequate. CSF analysis is a significant tool in diagnosis and differentiation from bacterial and viral meningitis. Conventional techniques of bacterial culture for identification of the pathogen are the gold standard but time-consuming and not available in a short time. However rapid detection methods like PCR are expensive and not available at the basic setup in low-income countries. Several biochemical and cytological variables are being used in differentiating from pyogenic, tubercular and viral meningitis. Though, there are several confines of the above variables in distinguishing bacterial from viral meningitis. Hence in this variability, an acute reliable marker is necessary to mark this which distinguish bacterial meningitis from incompletely treated meningitis and aseptic meningitis, ${ }^{[5]}$ though, several studies have recommended that CSF lactate proffers no extra clinically helpful details over conservative CSF markers. ${ }^{[6,7]}$ Various indicators, such as Creactive protein $(\mathrm{CRP}),{ }^{[8]}$ and procalcitonin, ${ }^{[9]}$ may authorize demarcation of patients with bacterial meningitis since those with aseptic meningitis. Though not any of the Mentioned markers are regularly utilized in clinical practice. ${ }^{[10]}$ Studies using lactate as a marker in the differentiation of bacterial and viral are limited in the Indian scenario. Hence the objective of the present research was to assess the effectiveness of CSF lactate in differentiating bacterial/ pyogenic from non-pyogenic meningitis.

\section{Subjects and Methods}

A hospital-based one-year prospective study was conducted at a tertiary care hospital in Gujarat. The study was performed at the department of General medicine for a period of one year. The study was presented before the institutional ethical committee and was accepted. The study procedure was elucidating to all the participants and written informed consent was acquired from them. All the cases suspected of meningitis above 18 years of age irrespective of sex were admitted and clinically evaluated. The analysis of meningitis was prepared on the foundation of clinical symptoms and signs like nausea, headache, fever, vomiting, altered sensorium, presence of kernig's sign, confusion, delirium, etc. All the cases were clearly examined and appropriate hematological, radiological investigations were performed immediately upon admission. Patients with conditions that may cause elevated levels of lactate in CSF like brain hypoxia, seizures, brain trauma, recent CVA, subarachnoid hemorrhage and cases on immunosuppressive therapy, fungal meningitis and HIV were debarred from the study. Lumbar puncture was done under strict aseptic precautions and $10 \mathrm{ml}$ of CSF collected and send to the central laboratory for estimation of all biochemical parameters like sugars, protein, lactate, cell counts, Adenosine deaminase (ADA) levels. CSF lactate was estimated by enzymatic method using ABL 555 blood gas analyzer. The reference range in this study was $1.2-2.1 \mathrm{mmol} / \mathrm{L}$ but ranges from $0.6-3.1 \mathrm{mmol} / \mathrm{L} .4$ the results of the CSF analysis were noted and based on findings the cases were grouped as,

- Pyogenic meningitis: Neutrophilic pleocytosis (10- 10000 cells/mm3), protein $>45 \mathrm{mg} / \mathrm{dl}$, sugar $<40 \mathrm{mg} / \mathrm{dl}$.

- Nonpyogenic: Tubercular or Viral meningitis.

\section{Tubercular}

Lymphocytic pleocytosis (10-1000cells $/ \mathrm{mm} 3)$. Protein $>45 \mathrm{mg} / \mathrm{dl}$, sugars $>2 / 3 \mathrm{rd}$ of blood sugar values, elevated ADA levels and demonstration of AFB on $\mathrm{Zn}$ staining.

\section{Viral}

Lymphocytic pleocytosis (25-500cells/mm3), slightly elevated protein $(20-80 \mathrm{mg} / \mathrm{dl})$, normal sugars and ADA levels without bacteria on staining.

\section{Statistical Analysis}

The data was analyzed using SPSS version 15 software (SPSS Inc., Chicago, Illinois, USA).

\section{Results}

The current prospective study was conducted by the department of General medicine and a total of 100 cases of meningitis which were diagnosed upon clinical evaluation were included in the study. The cases were grouped as pyogenic and nonpyogenic and viral and tubercular among the non-pyogenic group. With regard to the sex distribution of cases, 68 were males and 32 were females. The mean age of all the cases in the study was $37.50 \pm 1.6$ years. A hundred cases of meningitis were diagnosed with 46 cases being pyogenic and 54 cases non-Pyogenic. Of the 46 cases of pyogenic meningitis, 27 cases were tubercular and 19 cases were aseptic /viral meningitis. The majority of all the types of meningitis were observed in males. Fever was the most widespread indication follow by vomiting, headache and altered sensorium in of cases. [Table $1]$.

[Table 2]: Summarizes the findings of cytological parameters of different types of meningitis in this study. The mean total cell count was highest in cases of pyogenic meningitis with a mean of 840.50 and SD of 112.30 than viral and tubercular meningitis. However, no statistical significance was associated with total count and types of meningitis. $(\mathrm{P}>0.05)$ A clear neutrophil predominance was observed in all cases of pyogenic meningitis with a mean value of 79.10 and SD of 21.98 than among the cases of viral 
and tubercular meningitis. Lymphocytic predominance was observed in tubercular meningitis with a mean of 74.9 and SD of 23.12 than viral and pyogenic meningitis. Both PMN and lymphocyte count had a clear statistical significance. $(\mathrm{p} \leq 0.05)$

This study reveals that mean sugar levels are higher in viral than pyogenic and tubercular meningitis. Mean CSF protein was highest in pyogenic meningitis than viral and tubercular meningitis. In this study, no statistical significance was associated with sugar and protein levels in CSF and types of meningitis. Lactate levels of the CSF were elevated than normal in both pyogenic and tubercular than viral, however, the mean CSF lactate was higher in pyogenic than tubercular. A clear statistical significance was observed in CSF sugar/blood glucose ratio and CSF lactate levels in this study $(\mathrm{p} \leq 0.05)$. [Table 2]

When the cutoff value for CSF lactate was raised to $5 \mathrm{mmol} / 1$ and compared with tubercular and pyogenic meningitis, this study revealed that 20 cases of tubercular meningitis and 40 cases of pyogenic meningitis had elevated levels of CSF lactate $(>5 \mathrm{mmol} / \mathrm{l})$. A clear statistical significance was observed with levels of CSF lactate and type of meningitis in this study [Table $3]$.

\begin{tabular}{|c|c|c|c|}
\hline \multicolumn{2}{|c|}{ Clinical signs and symptoms } & Number & $\begin{array}{l}\text { Percentage } \\
(\%)\end{array}$ \\
\hline & Fever & 95 & 95 \\
\hline & Headache & 84 & 84 \\
\hline & Vomiting & 89 & 89 \\
\hline & Altered sensorium & 69 & 69 \\
\hline \multirow[t]{4}{*}{ Signs } & Neck stiffness & 65 & 65 \\
\hline & Kernig's sign & 61 & 61 \\
\hline & Brudzinski's sign & 78 & 78 \\
\hline & Cranial nerve palsy & 16 & 16 \\
\hline
\end{tabular}

* indicates statistically significant at $\mathrm{p} \leq 0.05$

* indicates statistically significant at $\mathrm{p} \leq 0.05$

\section{Discussion}

Pyogenic meningitis is connected with considerable morbidity and mortality and is a common and serious life-threatening disease. ${ }^{[11,12]}$ To discriminate between bacterial and viral meningitis, clinical findings have been apparent to have sensitivity and specificity within a range and are of less significance for differentiating among the types of meningitis. In only $60-80 \%$ of cases, direct CSF examination on an emergency basis provides evidence of bacterial meningitis. ${ }^{[13]}$ This study presently focused on the reliability and validity of CSF lactate as an indicator to distinguish pyogenic and non-pyrogenic cases of meningitis. The dimension of CSF lactate attentiveness is an easy, fast, economical test, requires only 15 minutes, which can be done at the bedside. In adding up, the CSF lactate application is helpful throughout the line of management; since quick CSF lactate reduction is analytic of high-quality prediction. ${ }^{[13]}$ The stop rate for CSF lactate concentration varies from 2.1-4.44 $\mathrm{mmol} / \mathrm{L}$ indicative of variation among tools, hospital labs and the technique. In this study, males outnumbered females with the most ordinary age group of 31-50 years. Comparable findings were reported in the study of van de Beek et al, with $75 \%$ of males and $25 \%$ of females. ${ }^{[14]}$ Mean age of the male was higher than the female in this study which is similar to many studies universally, but the noted feature of the study was the mean age of all the cases was $38.12 \pm 11.2$ years which is less than many studies conducted in the west and few studies in India. ${ }^{[15,16]}$ In this study, almost equal distribution of pyogenic and non-pyrogenic case distribution was observed with 59 pyogenic and 24 viral and 37 of tubercular meningitis. Fever was the most common symptom followed by vomiting, headache, and altered sensorium. Signs of meningeal irritation were observed in $20 \%$ of the cases only. Nerve palsies were identified in $21 \%$ of cases. However, these were not specific in differentiating pyogenic from nonpyogenic cases of meningitis. Few studies in the west reported a higher incidence of nerve palsies with $30-40 \%$ in their studies but this is quite variable depending upon the associated co-morbidities and age selection of cases in the study. ${ }^{[17,18]}$ This study revealed that mean total cell count was highest in cases of pyogenic meningitis with 840.50 and SD of 112.30 than viral and tubercular meningitis which is similarly reported in the study of Ranbeer Kumar Singh et al. Pyogenic meningitis showed neutrophil (PMN) predominance whereas non-pyogenic group showed lymphocyte predominance which was similar to findings of Ranbeer Kumar Singh et al, and was associated with the significant statistical association in this study. ${ }^{[9]}$ Baker RC et al and Viallon et al have found similar findings in their study with high CSF pleocytosis with neutrophil predominance in bacterial meningitis compared to viral meningitis. ${ }^{[19]}$ However, This study reveals that mean sugar levels are higher in viral and mean CSF protein was highest in pyogenic meningitis. Similar findings were reported in the study of Huy et al. Mean CSF protein was found to be highest in pyogenic meningitis followed by tubercular meningitis and viral meningitis. Similar findings were noted in studies done by Viallon et al with mean CSF protein $4.9 \_4.6 \mathrm{~g} / \mathrm{L}$ in bacterial meningitis versus $1 \_0.6 \mathrm{~g} / \mathrm{L}$ in viral meningitis. ${ }^{[9]}$ Ray $\mathrm{P}$ et al also noted similar findings in their study. ${ }^{[20]}$ This present study reveals the direct correlation of the mean CSF lactate level value with the mean CSF sugar to blood sugar ratio $(0.25)$ in the pyogenic meningitis group. The magnitude of CSF lactate level may also provide a clue in predicting poor outcomes and may also determine a likely 


\begin{tabular}{|lllll}
\hline \multicolumn{1}{|c|}{ Table 2: Analysis of CSF } & Lactate $(\mathbf{M m o l} / \mathbf{L})$ In a Different Group of Meningitis & & \\
\hline Type of meningitis & Lactate & & Total & P-value \\
\hline Tubercular & $\leq 2.1$ & $>2.1$ & & $0.001^{*}$ \\
Viral & 9 & 22 & 31 & \\
Pyogenic & 16 & 4 & 20 & \\
Total & 0 & 49 & 49 & \\
\hline
\end{tabular}

Table 3: Comparison of CSF Lactate between Tubercular and Pyogenic Meningitis with Cut Off of $5 \mathrm{mmol} / \mathrm{L}$

\begin{tabular}{|llll|l|}
\hline Type of meningitis & Lactate & & Total & P-value \\
\hline Tubercular & $\leq 5$ & $>5$ & & \\
\hline Pyogenic & 1 & 20 & 21 & $0.001^{*}$ \\
\hline Total & 3 & 40 & 43 & \\
\hline
\end{tabular}

prognosis which requires further evaluation and studies.

\section{Conclusion}

CSF lactate level is a quick, comparatively inexpensive and modest process that can be of immense worth as an indicative indicator in the premature differentiation of pyogenic meningitis and tubercular meningitis from viral meningitis, helping in the premature establishment of proper management and lessening mortality and complications. Early detection may help in early decision on the type and institution of appropriate management could reduce the mortality and morbidity of meningitis. Associated with CSF blood/CSF sugar ratio is also a helpful and supportive marker in differentiating viral, tubercular and pyogenic meningitis.

\section{References}

1. Ginsberg L, Kidd D. Chronic and recurrent meningitis. Pract Neurol. 2008;8(6):348-361. Available from: https://dx.doi.org/ 10.1136/jnnp.2008.157396.

2. Bacterial KR, Meningitis. Curr Treat Options Neurol. 1999;1:147-156.

3. Tunkel AR, Hartman BJ, Kaplan SL, Kaufman BA, Roos KL, Scheld WM, et al. Practice Guidelines for the Management of Bacterial Meningitis. Clin Infect Dis. 2004;39(9):1267-1284. Available from: https://dx.doi.org/10.1086/425368.

4. Tavares WM, Machado AG, Matushita H, Plese JPP. CSF markers for diagnosis of bacterial meningitis in neurosurgical postoperative patients. Arquivos de Neuro-Psiquiatria. 2006;64(3a):592-595. Available from: https://dx.doi.org/10. 1590/s0004-282x2006000400012.

5. Cunha BA. Distinguishing bacterial from viral meningitis: the critical importance of the CSF lactic acid levels. Intensive Care Med. 2006;32(8):1272-1273. Available from: https://dx.doi. org/10.1007/s00134-006-0210-x.
6. Gastrin B, Briem H, Rombo L. Rapid Diagnosis of Meningitis with Use of Selected Clinical Data and Gas-Liquid Chromatographic Determination of Lactate Concentration in Cerebrospinal Fluid. Int J Infect Dis. 1979;139(5):529-533. Available from: https://dx.doi.org/10.1093/infdis/139.5.529.

7. Ruuskanen O, Stãhlberg ML, Korvenranta H, Nikoskelainen J, Irjala K. CSF Lactate in Bacterial Meningitis with Minimal CSF Abnormalities. Acta Paediatr. 1985;74(2):292-293. Available from: https://dx.doi.org/10.1111/j.1651-2227.1985. tb10968.x.

8. Rajs G, Finzi-Yeheskel Z, Rajs A, Mayer M. C-Reactive Protein Concentrations in Cerebral Spinal Fluid in Grampositive and Gram-negative Bacterial Meningitis. Clin Chem. 2002;48(3):591-592. Available from: https://dx.doi.org/10. 1093/clinchem/48.3.591.

9. Santotoribio JD, Cuadros-Muñoz JF, García-Casares N. Comparison of C Reactive Protein and Procalcitonin Levels in Cerebrospinal Fluid and Serum to Differentiate Bacterial from Viral Meningitis. Ann Clin Lab Sci. 2018;48(4):506-10.

10. Roos KL, Tyler KL. Meningitis, Encephalitis, Brain Abscess, and Empyema. Harrison's Principles of Internal Medicine. New York; 2004.

11. Holub M, Beran O, Dzypova O, Hnykoya J, Lacinova Z, Prihodova J. Cortisol levels in cerebrospinal fluid correlate with severity and bacterial origin of meningitis. Crit Care. 2007;11(2):41-41. Available from: https://doi.org/10.1186/ cc5729.

12. Harrell A, Durack FE, T D. Differential diagnosis of acute meningitis: an analysis of the predictive value of initial observations. JAMA. 1989;262(19):2700-2707.

13. Genton B, Berger JP. Cerebrospinal fluid lactate in 78 cases of adult meningitis. Intensive Care Med. 1990;16(3):196-200. Available from: https://dx.doi.org/10.1007/bf01724802.

14. van de Beek D, de Gans J, Spanjaard L, Weisfelt M, Reitsma JB, Vermeulen M. Clinical Features and Prognostic Factors in Adults with Bacterial Meningitis. N Engl J Med. 2004;351(18):1849-1859. Available from: https://dx.doi.org/ $10.1056 /$ nejmoa040845. 
15. Heyderman RS, Lambert HP, O’Sullivan I, Stuart JM, Taylor BL, Wall RA. Early Management of Suspected Bacterial Meningitis and Meningococcal Septicaemia in Adults. J Infect. 2003;46(2):75-77. Available from: https://dx.doi.org/10.1053/ jinf.2002.1110.

16. Jagadish G, Asuti S, Narayan A. Estimation of CSF lactate as a diagnostic marker to differentiate pyogenic meningitis from nonpyogenic meningitis. J Neurosci. 2019;5(3):106-112. Available from: https://dx.doi.org/10.18231/j.ijn.2019.015.

17. Chavanet P, Schaller C, Levy C, Flores-Cordero J, Arens M, Piroth L, et al. Performance of a predictive rule to distinguish bacterial and viral meningitis. J Infect. 2007;54(4):328-336. Available from: https://dx.doi.org/10.1016/j.jinf.2006.06.009.

18. Singh K, Usmani R, Haque F, Tanweeruddin SS, Singh M, K B. Estimation of Lactate Dehydrogenase Activity in cerebrospinal fluid in different types of meningitis. Int J Adv Biolog Biomed Res. 2017;5(1):48-51.

19. Baker RC, Lenane AM. The predictive value of cerebrospinal fluid differential cytology in meningitis. Pediatr Infect Dis J. 1989;8(5):329-359.
20. Ray P, Badarou-Acossi G, Viallon A, Boutoille D, Arthaud M, Trystram D, et al. Accuracy of the cerebrospinal fluid results to differentiate bacterial from non bacterial meningitis, in case of negative gram-stained smear. Am J Emerg Med. 2007;25(2):179-184. Available from: https://dx.doi.org/10. 1016/j.ajem.2006.07.012.

Copyright: (C) the author(s), 2020. It is an open-access article distributed under the terms of the Creative Commons Attribution License (CC BY 4.0), which permits authors to retain ownership of the copyright for their content, and allow anyone to download, reuse, reprint, modify, distribute and/or copy the content as long as the original authors and source are cited.

How to cite this article: Patel MK, Patel HJ. Evaluation of Lactate in Differentiating Pyogenic and Non-Pyogenic Meningitis. Acad. J Med. 2020;3(2):37-41.

DOI: dx.doi.org/10.47008/ajm.2020.3.2.9

Source of Support: Nil, Conflict of Interest: None declared. 